\title{
Avaliação de um Sistema de Geração, Armazenagem e Distribução de Água Purificada em uma Indústria de Cosméticos
}

\author{
Rafaella P. Malgueira, Leandro F. Mendonça, Marta C. Picardo \& Leticia Q. \\ Pereira
}

A água é um recurso de grande relevância para a indústria de cosméticos, sendo sua principal matéria-prima, impactando diretamente na qualidade do produto final. Com as crescentes exigências da Agência Nacional de Vigilância, surge a necessidade de utilização de água purificada, livre de íons inorgânicos e contaminação microbiológica. Este trabalho buscou estudar um sistema, utilizando resina de troca iônica e esterilizadores de radiação ultravioleta, para a geração, armazenagem e distribuição de água purificada em uma indústria de cosméticos. Identificaram-se os pontos críticos do sistema, foram propostas melhores condições técnicas para garantir maior eficácia e melhor controle microbiológico e físico-químico.

Palavras-chaves: resina de troca iônica; esterilizadores de radiação ultravioleta; otimização de processos.

Water is a highly important resource to the cosmetic industry, it is the main raw material and directly impacts the quality of the final product. With the growing demands of the Brazilian Health Regulatory Agency (ANVISA), the need arises to use purified water as raw material, free of inorganic ions and microbiological contamination. This paper studies a purified water generation, with ion exchange resins to deionize water and ultraviolet radiation sterilizers storage and distribution system in a cosmetics industry. The system's critical points were identified, opportunities for improvement were found and better technical conditions have been proposed to ensure greater effectiveness and improved microbiological, physical and chemical control.

Key-words: ion exchange resin; ultraviolet radiation sterilizers; process optimization. 


\section{Introdução}

A indústria de cosméticos é responsável pela fabricação de produtos constituídos por substâncias naturais ou sintéticas de uso externo nas diversas partes do corpo humano, como cabelo e pele, cujo objetivo principal é limpar, perfumar, alterar a aparência, corrigir odores corporais ou proteger ${ }^{1}$.

$\mathrm{Na}$ indústria de cosméticos, a utilização da água é um fator de grande relevância, tanto em relação à quantidade quanto em relação aos cuidados necessários para se obter a qualidade desejada para a condução dos processos de produção ${ }^{2,3}$.

Além disso, a água é a principal matéria-prima, estando presente em quase todas as formulações desenvolvidas e em grande quantidade na composição dessas. A qualidade da água e de outras bases cosmetológicas é, em muitos casos, até mais importante do que os ativos, pois permitirá melhor ação dos ativos funcionais presentes na formulação e maior eficácia do cosmético ${ }^{4}$.

Ao utilizar a água que chega à indústria diretamente da rede de abastecimento estadual como matéria-prima, o produto cosmético final está sujeito a diversas alterações em sua qualidade como formação de resíduos, alteração da cor, formação de colônias visíveis de microrganismos, separação das fases de uma emulsão, dentre outras, devido às impurezas presentes nesta água ${ }^{5}$.

Além das alterações na qualidade do produto, um cosmético fabricado com água contaminada por microrganismos apresenta um forte risco à saúde do consumidor, pois em contato com a pele, principalmente se estiver ferida, poderá ocasionar uma infecção ${ }^{5}$.

A Agência Nacional de Vigilância Sanitária (ANVISA) está aumentando as exigências e fiscalizações nas empresas, chegando a autuar ou cancelar registros de produção de indústrias que apresentem descuidos com a qualidade da água e de seus produtos finais ${ }^{6}$.

Dentro desse cenário, surge a necessidade de um tratamento para obtenção de água com maior qualidade. Apesar de existir o padrão de água ultrapura (UPW), muito utilizado pela indústria farmacêutica, o tipo de água geralmente recomendado para uso nas indústrias de cosméticos é chamado de PW (Pure Water) ou água purificada ${ }^{6}$.

A obtenção de água purificada se dá de três formas na indústria cosmética: destilação, troca iônica ou osmose reversa. O trabalho dá ênfase na troca iônica, pois é o processo utilizado no projeto do sistema de geração de água purificada ${ }^{5}$.

$\mathrm{Na}$ destilação ocorre a remoção de íons e outros componentes orgânicos, além de remover também outros contaminantes presentes na água, como bactérias, endotoxinas e matéria orgânica. Como desvantagem, é que para a obtenção de um volume considerável de água destilada, é necessário utilizar muita água comum, gerando desperdício de água potável e um alto consumo de energia?

Com relação à osmose reversa, empregam-se membranas sintéticas porosas com tamanhos de poros tão pequenos que filtram os sais dissolvidos na água. Apesar de comprovadamente eficaz do ponto de vista tecnológico, as unidades de osmose reversa já instaladas têm apresentado problemas operacionais e de manutenção, pois poucas empresas dominam e comercializam a tecnologia, o que contribui, também, para o aumento dos preços ${ }^{8-11}$.

$\mathrm{O}$ processo de deionização, realizado com colunas de troca iônica, é muito utilizado devido à simplicidade da técnica, a durabilidade das resinas, a versatilidade, ao baixo custo, entre outras vantagens ${ }^{12}$. É o método mais utilizado nas indústrias cosméticas devido a algumas vantagens como a simplicidade da técnica, baixo custo, durabilidade das resinas, possibilidade de combinações com outras técnicas, versatilidade, fácil operação, alta pureza do produto obtido, rápida restauração das resinas após saturação e possibilidade de utilização da água diretamente da rede de abastecimento estadual 2, 12-14.

Além disso, o emprego de resinas de troca iônica evita desperdícios de água, pois não há liberação de rejeitos como na osmose reversa; e de energia, tendo em vista que as resinas não necessitam de energia elétrica ${ }^{13}$.

Após passar pelas resinas de troca iônica, a água ainda precisa ser submetida a um processo de controle microbiológico utilizando um esterilizador de radiação 
ultravioleta (UV) após a saída da água dos leitos de troca iônica ${ }^{13}$.

A irradiação por lâmpadas de raios ultravioletas é efetiva na eliminação de todos os tipos de bactérias encontradas na água. As vantagens do sistema de irradiação por ultravioleta são o baixo custo de manutenção e o baixo tempo de retenção ${ }^{14}$.

Este trabalho visa estudar o sistema de geração, distribuição e armazenagem de água purificada, por troca iônica, em uma indústria de cosméticos localizada no Rio de Janeiro, propondo melhorias na eficiência do processo, na qualidade da água, no controle físicoquímico e microbiológico.

\section{Materiais e Métodos}

Os dados e informações utilizados para o desenvolvimento do trabalho foram coletados por meio dos seguintes meios: avaliação de documentação disponível na empresa em estudo, como análises físico-químicas e microbiológicas da água em todos os seus pontos de amostragem no decorrer do sistema de geração, armazenagem e distribuição de água purificada; manuais de operação; relatórios; dentre outros.Observação e avaliação das atividades realizadas na planta industrial, acompanhando as operações de pesagem de matéria-prima, fabricação, envase, limpeza e sanitização de equipamentos, além de acompanhamento nas etapas de laboratório como pesquisa e desenvolvimento de produtos, estudos de estabilidade e análises físico-químicas.Inspeções nas instalações industriais, tanto no sistema de água purificada, quanto no restante da planta industrial. Medição de dados de operação do sistema coletados por instrumentos localizados em pontos de amostragem específicos do sistema.

Após a análise dos pontos críticos do sistema, foram elaboradas propostas para otimizá-lo em todas as suas partes, relacionadas ao controle físico-químico e microbiológico e ao aumento da eficiência do sistema.

\section{Resultados e Discussões}

Para a realização da análise microbiológica e físicoquímica, as amostras de águas fornecida pela Companhia Estadual de águas e esgoto (CEDAE) foram coletadas mensalmente, por quatro meses. Essas avaliações permitiram identificar que a água apresenta resultados dentro dos parâmetros de potabilidade, conforme especificação. Dessa forma, está apta para ser utilizada pela empresa para fins como higiene pessoal dos funcionários, irrigação de jardins, limpeza de áreas externas, dentre outros.

Porém, de acordo com os parâmetros estabelecidos para água purificada, a água vinda da CEDAE obedece apenas aos parâmetros de odor, $\mathrm{pH}$, coliformes totais e Escherichia coli. Os parâmetros de Cloro livre $\left(\mathrm{Cl}_{2}\right)$, Cálcio e Magnésio que precisam estar ausentes na água purificada, encontramse em quantidades pequenas, portanto, não está apta para ser utilizada como matéria-prima para cosméticos.

A água, após a purificação pelo sistema da empresa, também foi avaliada pelos parâmetros citados acima. Os resultados mostraram que apesar de a análise ter indicado ausência de coliformes fecais e coliformes totais, apresentou bactérias do tipo mesófilas, com unidades formadoras de colônias (UFC) muito acima da especificação de $100 \mathrm{UFC} / \mathrm{mL}$ (Tabela 1). Isso evidencia que o controle microbiológico do processo de geração, distribuição e o armazenamento da água não está sendo realizado de forma adequada ${ }^{15}$.

Além disso, foi possível identificar alterações nos valores de $\mathrm{pH}$ e condutividade logo na saída das colunas de troca iônica. $\mathrm{O}$ valor alterado de condutividade, acima de $10 \mu \mathrm{S} / \mathrm{cm}$, indica a presença de íons, tanto cátions quanto ânions na água, evidenciando que a troca iônica não está ocorrendo de maneira eficiente, de acordo com a Tabela 2.

$\mathrm{O}$ valor de $\mathrm{pH}$ abaixo do especificado, ou seja, abaixo de 5,0 indica que a água deionizada pelas resinas de troca iônica está saindo com excesso de íons $\mathrm{H}^{+}$. Logo, sugere-se ineficiência da resina aniônica que não está retendo os ânions e liberando os íons $\mathrm{OH}^{-}$responsáveis por neutralizar a água decationizada (água ácida) que sai da resina catiônica. 
Tabela 1. Dados de análises microbiológicas da água purificada

\begin{tabular}{|c|c|c|c|c|c|c|}
\hline Parâmetros & Especificação & $\mathbf{1 0 / 0 1 / 1 7}$ & $\mathbf{1 7 / 0 1 / 1 7}$ & $\mathbf{2 4 / 0 1 / 1 7}$ & $\mathbf{0 7 / 0 2 / 1 7}$ & $\mathbf{2 8 / 0 3 / 1 7}$ \\
\hline $\begin{array}{c}\text { Contagem } \\
\text { mesófilas }\end{array}$ & $100 \mathrm{UFC} / \mathrm{mL}$ & 6700 & 210 & 3200 & 4300 & 2400 \\
\hline $\begin{array}{c}\text { Coliformes } \\
\text { totais }\end{array}$ & Ausência & Ausência & Ausência & Ausência & Ausência & Ausência \\
\hline $\begin{array}{c}\text { Coliformes } \\
\text { fecais }\end{array}$ & Ausência & Ausência & Ausência & Ausência & Ausência & Ausência \\
\hline $\begin{array}{c}\text { Pseudomonas } \\
\text { aeruginosa }\end{array}$ & Ausência & Ausência & Ausência & Ausência & Ausência & Ausência \\
\hline
\end{tabular}

Tabela 2. Dados de análises físico-químicas da água purificada

\begin{tabular}{|c|c|c|c|c|c|c|}
\hline Parâmetros & Especificação & $\mathbf{1 7 / 1 0 / 1 6}$ & $\mathbf{2 0 / 1 0} / \mathbf{1 6}$ & $\mathbf{2 4 / 1 0} / \mathbf{1 6}$ & $\mathbf{0 8 / 1 1 / 1 6}$ & $\mathbf{1 2 / 1 1 / 1 6}$ \\
\hline Odor & Inodoro & Inodoro & Inodoro & Inodoro & Inodoro & Inodoro \\
\hline $\mathrm{pH}\left(25^{\circ} \mathrm{C}\right)$ & 5,0 a 9,0 & 9,28 & 4,80 & 9,88 & 5,23 & 6,25 \\
\hline Cloro livre & Ausente & Ausente & Ausente & Ausente & Ausente & Ausente \\
\hline Condutividade & 0 a $10 \mu \mathrm{S} / \mathrm{cm}$ & 11,85 & 27,94 & 13,55 & 11,07 & 15,16 \\
\hline
\end{tabular}

$\mathrm{O}$ valor de $\mathrm{pH}$ acima do especificado, ou seja, acima de 9,0 indica que a água deionizada pelas resinas de troca iônica está saindo com excesso de íons $\mathrm{OH}^{-}$. Logo, sugerese ineficiência da resina catiônica que não está retendo os cátions e em consequência não está liberando os íons $\mathrm{H}+$. A alteração dos valores de $\mathrm{pH}$ e condutividade da água purificada pode ser facilmente solucionada realizando o processo de regeneração das resinas de troca iônica.

As Figura 1 e 2 apresentam o esquema do processo de tratamento de água, que atua desde o recebimento dessa pela CEDAE até a linha de distribuição na área de fabricação.

Diante dos resultados apresentados que estão fora dos padrões aceitáveis para a aplicação da água na indústria de cosméticos, foram sugeridas algumas modificações no sistema de geração, armazenagem e distribuição da água purificada.

O novo projeto, para a otimização do processo, propõe a inutilização de um dos tanques de armazenamento e em consequência, a bomba que está acoplada a ele. Somente um tanque possui capacidade maior do que a demanda diária da empresa (8.000 litros) e, além disso, o sistema pode operar continuamente não oferecendo riscos da produção parar devido a falta de água purificada. Ademais, para garantir que a produção não fique sem sua matéria-prima principal, a água, será instalado um controlador de nível no tanque de armazenamento, a fim de mantê-lo sempre em um nível preestabelecido. Sempre que esse nível baixar, o controlador comunicará o sistema para geração de água. Será, também, instalado na saída do tanque de armazenagem a fim de medir a pressão de distribuição para a linha de fabricação.

Quanto ao sistema de distribuição, terá sua tubulação totalmente substituída e reduzida para aproximadamente 150 metros, removendo. assim, trechos desnecessários e pontos de curva que geram maior perda de carga no sistema e onde há maior probabilidade de proliferação de microrganismos. O material ideal da tubulação, segundo a ANVISA (2013a), para esse tipo de caso com exigência sanitária, é o aço inoxidável 316L (baixo teor de carbono). 


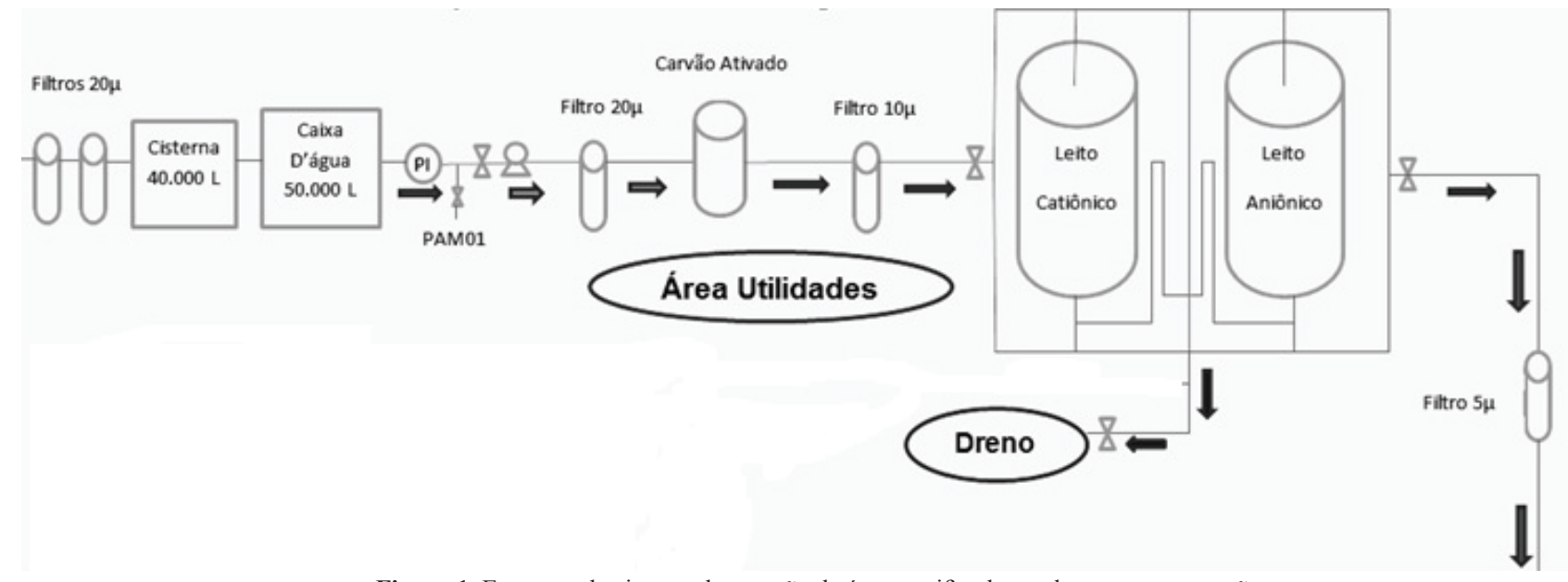

Figura 1. Esquema do sistema de geração de água purificada atualmente em operação.

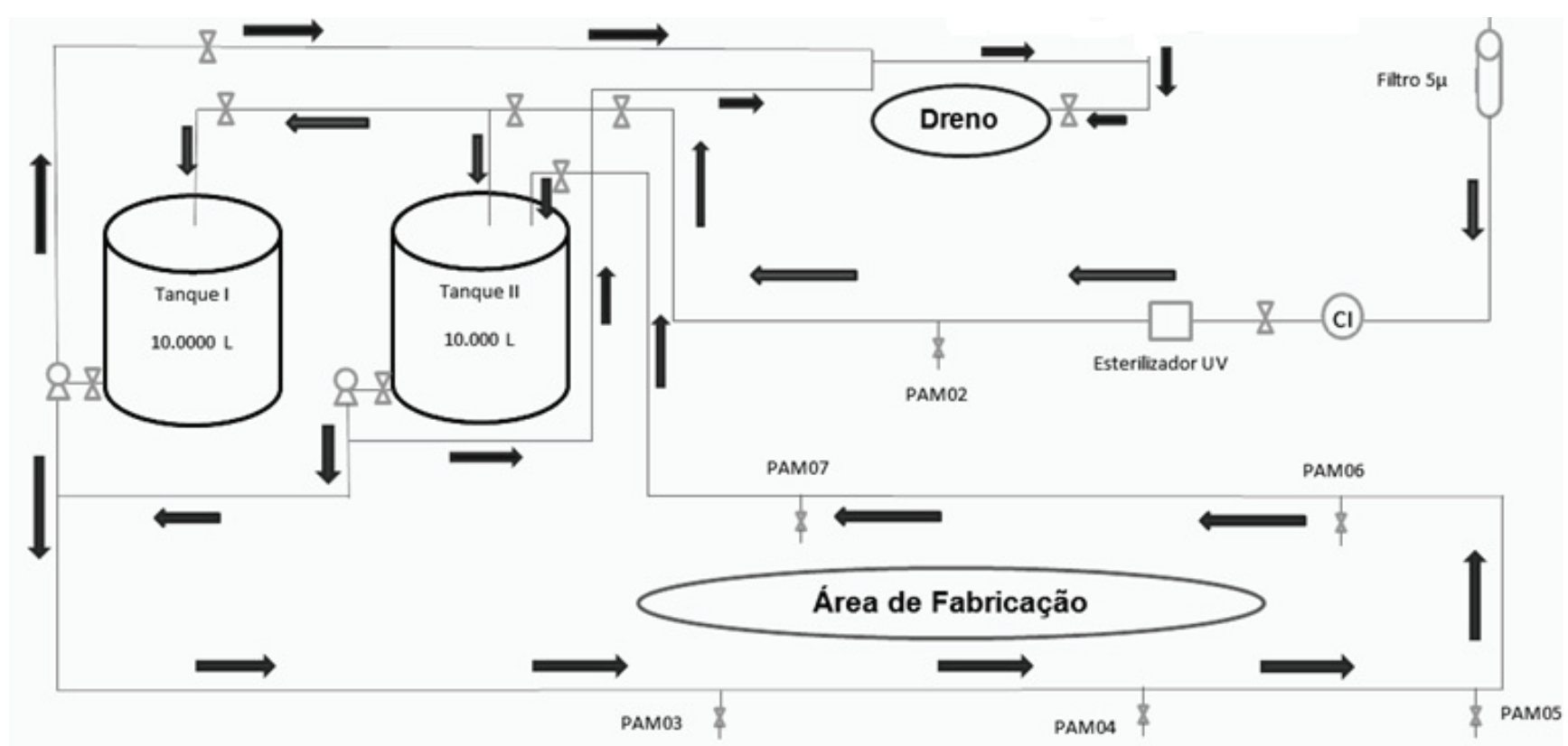

Figura 2. Esquema do sistema de armazenagem e distribuição de água purificada atualmente em operação.

Um terceiro manômetro será instalado no final da linha de distribuição, antes do último ponto de fabricação, para controlar a pressão no decorrer da tubulação. $\mathrm{O}$ anel de distribuição terá circulação contínua, isto é, a água, após sair do tanque de armazenamento e percorrer toda a linha de distribuição, irá voltar para o tanque e recircular continuamente, 24 horas por dia, durante todos os dias do mês.

A bomba do tanque que foi inutilizado será retirada e instalada em paralelo junto à bomba do tanque em funcionamento. Isso garante que, em caso de problema com 
a bomba em funcionamento, o fluxo de água poderá ser desviado para passar a percorrer a outra bomba e o sistema poderá continuar operando normalmente.

Um anel de distribuição de água sem recirculação pode ser considerado um "ponto-morto" no sistema, favorecendo a proliferação de microrganismos. A circulação contínua de água purificada na linha de distribuição, além de diminuir significativamente a possibilidade de contaminação microbiana da água, facilitará o processo de sanitização da tubulação.

Antes do último ponto de uso para fabricação e em consequência, antes da saída da água da linha de distribuição na área de fabricação e antes de entrar novamente no tanque de armazenagem, será instalado mais um esterilizador ultravioleta a fim de assegurar o controle microbiológico após a água ter passado por toda a tubulação.

Os pontos de amostragem da linha de distribuição serão mantidos para a realização de análises físicoquímicas e microbiológicas constantes que ajudarão a controlar e manter a qualidade da água sempre dentro dos padrões estabelecidos. São esses: PAM04, localizado no início da linha de distribuição com a finalidade do controle da entrada da água na fabricação; PAM05, PAM06 e PAM07, localizados nos três primeiros pontos de uso para fabricação com a finalidade de controle da água em cada lote de produção; e o PAM08 localizado no quarto e último ponto de uso para fabricação e no final da linha de distribuição, após passagem pelo segundo esterilizador ultravioleta, para garantia de que a água que volta ao tanque de armazenamento está dentro dos padrões estabelecidos mesmo após percorrer toda a tubulação.

Tavares e outros ${ }^{13}$ desenvolveram um estudo experimental em laboratório, utilizando colunas de troca iônica para a desmineralização da água e a utilização de um esterilizador por radiação ultravioleta para garantir a pureza microbiológica após a purificação química. Os resultados do estudo foram bastante satisfatórios, e os autores concluíram que com a utilização de colunas preenchidas com resinas de troca iônica é possível a obtenção de água de excelente qualidade química e microbiológica.
Baseado em todas as propostas, foi criado or meio do software de criação de fluxogramas, DIA, o fluxograma do sistema proposto representado na Figura 2.

Para a garantia da qualidade da água deve-se ter atenção em manter toda a superfície interna e externa do sistema de purificação de água em condições de higiene.

A limpeza interna, externa e total deve ser realizada antes do processo de sanitização, e a limpeza interna dos tanques de armazenamento é realizada uma vez por mês com água potável e detergente neutro por toda a superfície interna dos tanques.

Como a condutividade da água medida na saída das colunas de deionização, após o esterilizador por radiação UV, registrou acima do limite de aceitação, é necessário realizar a regeneração das resinas.

\section{Conclusão}

Em função da análise dos parâmetros de qualidade da água proveniente da rede pública de abastecimento, conclui-se que não é possível utilizá-la como matéria-prima sem antes submetê-la a um processo de purificação para controle físico-químico e microbiológico.

A presença de unidades formadoras de colônia muito acima da especificação indicou que o controle microbiológico do sistema de geração, armazenagem e distribuição não está sendo realizado de maneira adequada e, com isso, comprovou-se a necessidade da melhoria.

Dessa forma, uma série de melhorias foram propostas para aprimorar a eficiência do processo como um todo, para aumentar o controle microbiológico e o controle físico-químico. Entre elas, a inutilização de um dos tanques de armazenamento; a construção de uma ramificação para ligação de um tambor contendo solução sanitizante; a adição de pontos de amostragem para realização das análises físico-químicas e microbiológicas em locais estratégicos; a inutilização de duas bombas do sistema; a adição de um novo esterilizador de radiação ultravioleta; e a implementação de circulação contínua da água pelo sistema. 


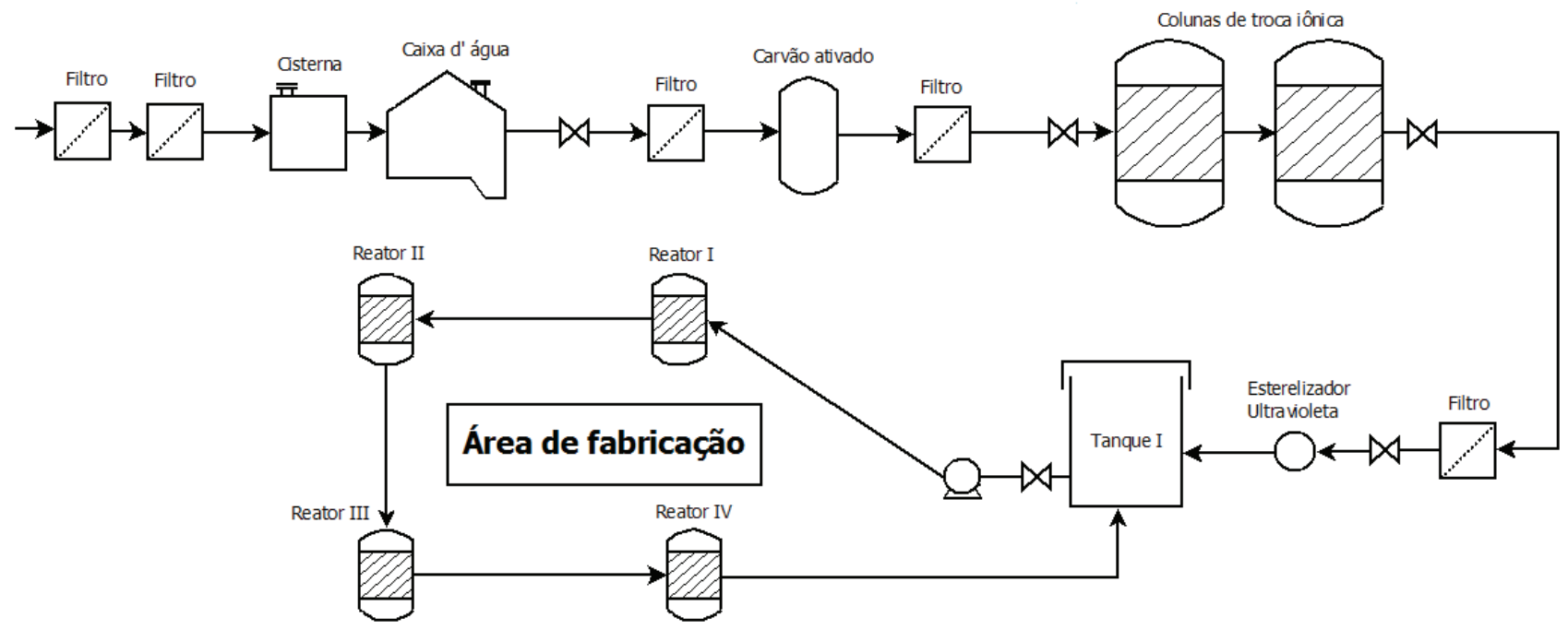

Figura 3. Fluxograma do sistema proposto.

\section{Referências}

1. Abdi. Relatório de acompanhamento setorial: cosméticos. São Paulo: vol. 1, 2008.

2. Alves, S. S. Conservação e reuso de água em indústria de cosméticos: estudo de caso da Natura cosméticos. 2009. Dissertação (Mestrado em Engenharia) - Escola Politécnica, Universidade de São Paulo, São Paulo, 2009.

3. Furtado, Marcelo. Desmineralização da água: cliente mais maduro gera demanda por produtos e serviços especializados. 2003.

Disponível em: < http://www.quimica.com.br/desmineralizacao-deagua-cliente-mais-maduro-gera-demanda-por-produtos-e-servicosespecializados-2/>. Acesso em 10 de fevereiro de 2017.

4. Hernandez, Micheline.; Fresnel, M. M. M. Manual de Cosmetologia. 3 ed. Rio de Janeiro: Revinter, 1999.

5. Wilkinson, J.B.; Moore, R.J. Cosmetologia de Harry. 1 ed. Madrid: Diaz de Santos, 1990.

6. Furtado, Marcelo. Água ultrapura: Anvisa e receio de contaminação forçam setor cosmético a melhorar água. 2013. Disponível em $<$ http://www.quimica.com.br/agua-ultra-pura-anvisa-receiocontaminacao-forcam-setor-cosmetico-melhorar-agua/>. Acesso em 24 de fevereiro de 2017.
7. PERMUTION. Destilação ou deionização. Paraná. Disponível em: $<\mathrm{http}$ ://www.permution.com.br/destilacao-ou-deionizacao-eis-aquestao/>. Acesso em 13 de maio de 2017.

8. Scapini, Luciana. Avaliação do desempenho da osmose reversa e da troca iônica para tratamento de efluente de curtume (Aimoré Couros LTDA - Encantado) visando à reutilização da água. 2007. Dissertação (Mestrado em Sistemas e Processos Industriais) Universidade de Santa Cruz do Sul, Rio Grande do Sul, 2007.

9. Oliveira, F. C.; Pelegrini, D. D. Controle de qualidade do sistema de produção de água purificada obtida por osmose reversa em indústria farmacêutica. Paraná: Rev. Saúde e Biol., 2011, 6, 36.

10. Klimeck, C. A. et al. Uso de água tratada por osmose reversa para a geração de vapor em indústria de tabaco. Santa Catarina: Revista Produção Online, 2012, 12, 522.

11. Jesus, G. O. et al. Destilação de água por energia solar. Bahia: Cad. Prospec. 2015, 8, 469.

12. Trivelin, P. C. O.; Bendassoli, J. A.; Carneiro, F. Sistema desmineralizador de água de alta eficiência e baixo custo utilizando resinas trocadoras de íons. São Paulo: Química Nova, 1995. 19.

13. Tavares, G. A.; Bensassolli, J. A.; Souza, G.; Nolasco, F. Implantação de uma estação de produção de água desionizada para uso nos laboratórios do CENA/USP empregando resinas de troca iônica. São Paulo: Revista Analytica, n. 10, 2004. 


\section{Artigo Geral 6}

14. Cunha, O. A. A. Água desmineralizada para indústria cosmética. Cosmetics \& Toiletries, v.3, p. 22-28, 1991.

15. Ferreira, H.; Lima, H.; Coelho, Thiago. Microrganismos indicadores em alimentos de origem animal. 2014. Trabalho apresentado como requisito parcial para aprovação na Disciplina de Tópicos Avançados em Microbiologia de Alimentos de Origem Animal, Programa de Pós-Graduação em Ciência Animal, Universidade Federal Rural do Semiárido, Rio Grande do Norte, 2014.

\section{Rafaella P. Malgueira', Leandro F.} Mendonça², Marta C. Picardo' \& Leticia Q. Pereira ${ }^{1 *}$

${ }^{1}$ SENAI CETIQT. Rua Magalhães Castro 174,

Riachuelo, CEP: 20961-020 - Rio de Janeiro - RJ

${ }^{2}$ MARCIA COSMÉTICOS. Rua Correa Dias, 180 -

Vigário Geral, CEP: 21241-310 - Rio de Janeiro - RJ.

*E-mail: lquinello@cetiqt.senai.br 